\section{Porcine foetal and neonatal CYP3A liver expression}

\author{
Marie Louise Hiort Hermann, ${ }^{1,2}$ \\ Mette Tingleff Skaanild ${ }^{1}$ \\ 'Department of Veterinary Disease \\ Biology, Faculty of Life Science, \\ University of Copenhagen; \\ ${ }^{2}$ National Veterinary Institute, Technical \\ University of Denmark
}

\section{Abstract}

Human cytochrome P450 3A7 (CYP3A7) and cytochrome P450 3A4 (CYP3A4) are hepatic metabolising enzymes which participates in the biotransformation of endo- and exogenous substances in foetuses and neonates respectively. These CYP3A enzymes display an inverse relationship: CYP3A7 is the dominant enzyme in the foetal liver, whereas the expression of CYP3A4 is low. After parturition there is a shift in the expression, thus CYP3A7 is down regulated, while the level of CYP3A4 gradually increases and becomes the dominant metabolising CYP3A enzyme in the adult. The minipig is increasingly being used as a model for humans in biomedical studies, because of its many similarities with the human physiology and anatomy. The aim of this study was to examine whether, as in humans, a shift is seen in the hepatic expression of a CYP3A7like enzyme to cytochrome P450 3A29 (CYP3A29) (an orthologue to the human CYP3A4) in minipigs. This was elucidated by examining the hepatic mRNA expression of CYP3A7 and CYP3A29 in 39 foetuses and newborn Göttingen minipigs using quantitative real time polymerase chain reaction (qPCR). Furthermore the immunochemical level of CYP3A7-LE and CYP3A29 was measured in liver microsomes using western blotting. The expression of CYP3A29 was approximately 9fold greater in neonates compared to foetuses, and a similar difference was reflected on the immunochemical level. It was not possible to detect a significant level of foetal CYP3A7 mRNA, but immunoblotting showed a visible difference depending on age. This study demonstrates an increase in the expression of CYP3A29, the CYP3A4 orthologue in perinatal minipigs as in humans, which suggests that the minipig could be a good model when testing for human foetal toxicity towards CYP3A4 substrates.

\section{Introduction}

To gain knowledge of pharmacological and toxicological properties of new chemical compounds they are studied using laboratory animals. However some metabolic difference exists among species, which complicates the extrapolation of results from animal models to humans. ${ }^{1}$ For this reason it is relevant to clarify, whether the species used in these experiments have metabolising characteristics comparable to humans.

Since the 1980 s, the minipig has been a popular alternative to the traditional nonrodent species in pharmacology and toxicology studies because of its many similarities with the human physiology and anatomy. ${ }^{2-4}$ It has been shown that the expression of a minipig cytochrome P450 3A (CYP3A) enzyme is comparable with the human cytochrome P450 3A4 (CYP3A4) enzyme. ${ }^{5,6}$ However it is unknown whether the minipig foetus and the human foetus express comparable metabolising enzymes.

Human CYP3A constitute some of the most important hepatic isoenzymes as they account for 30 percent of the total cytochrome P450 complex. $^{7}$ It is assumed that CYP3A isoenzymes are involved in the biotransformation of more than half of the therapeutic agents which undergo metabolic oxidation. ${ }^{8}$ Two human CYP3A, CYP3A4 and cytochrome P450 3A7 (CYP3A7), exhibit an inverse expression pattern. ${ }^{9-11}$ In minipigs however only one of these isoenzymes, the CYP3A4 like enzyme, has been characterized and the mRNA sequenced.

CYP3A7 has been termed foetus-specific, as this is the dominant isoenzyme in the liver of human foetuses until birth. Its hepatic expression has been demonstrated as early as $\mathbf{5 0}$ days after conception. ${ }^{9,12-14}$ Around time of birth the expression of CYP3A7 is remarkably reduced whereas the expression of CYP3A4 gradually increases. Within the first year of life, the hepatic CYP3A7 level declines to very low quantities and CYP3A4 becomes the dominant isoenzyme in the liver of adult. ${ }^{9-11,15}$

During foetal development the hepatic CYP3A4 expression accounts for less than 10\% of the adult level until birth, after which the expression gradually increases and becomes the dominant CYP3A isoform in the liver of adults, ${ }^{9,16}$ playing a considerable role in the biotransformation of xenobiotics. ${ }^{17}$

The cytochrome P450 3A29 (CYP3A29) isoenzyme of pigs and minipigs have been shown to have similar enzymatic activity to the human CYP3A4 $4^{6,18,19}$ and Anzenbacherova et $a l .{ }^{20}$ found that the binding site of CYP3A29 and CYP3A4 is well conserved, suggesting that these enzymes share common characteristics. As the human foetus has a metabolism independently of the mother, it is important that
Correspondence: Mette Tingleff Skaanild Department of Veterinary Disease Biology Ridebanevej 9 DK 1870 Frederiksberg C, Denmark. Tel: +45.35.333175 - Fax: +45.35353514 .

E-mail:mts@life.ku.dk

Key words: minipig, liver, CYP3A7, CYP3A29, neonate, foetus.

Acknowledgments: this project was supported by Ellegaard Göttingen minipig A/S, DK- 4261 Dalmose, Denmark.

Received for publication: 7 February 2011 Accepted for publication: 6 April 2011.

This work is licensed under a Creative Commons Attribution 3.0 License (by-nc 3.0).

(OCopyright M.L.H. Hermann and M.T. Skaanild, 2011 Licensee PAGEPress, Italy

Journal of Xenobiotics 2011; 1:e1

doi:10.4081/xeno.2011.e1

the species used to test for foetal toxicity exhibit a metabolism resembling the metabolism of human foetuses. The animal species most used when testing for teratogenicity are the mouse and rat classified as rodents, and the rabbit as the non-rodent species. ${ }^{21,22}$

Since minipigs increasingly are being used in pharmacological and toxicological tests, the aim of this study was, to examine the hepatic expression profile of CYP3A enzymes of foetuses and newborn Göttingen minipigs. This was investigated to clarify whether there exists a comparable shift in the expression from a CYP3A7-like enzyme to CYP3A29 around the time of birth, supporting the use of this species as model for human foetal toxicity.

\section{Materials and Methods}

\section{Animals}

Liver tissue was obtained from 39 Göttingen minipigs: 19 foetuses (9 males and 10 females) approximately 100 days after fertilization and 20 neonates (10 males and 10 females) about 24 hours old. Dams were fed commercial chow restrictively and provided with water ad libitum. No CYP induction was performed. The dams were killed by use of captive bolt pistol and exsanguination. The placenta containing the foetuses was retrieved from the dam just after it was killed. This procedure was chosen to avoid any influence on gene expression. The foetuses were killed by decapitation and neonates were killed by a blow to the head followed by decapitation and exsanguination. Handling of the animals was performed by experienced, authorized people and in accordance to Danish legislation. Liver 
tissue was removed and frozen within 10 to 15 minutes. Liver samples for RNA later were obtained from lobus hepatis sinister medialis, the rest of the liver was put on dry ice and afterwards stored at $-80^{\circ} \mathrm{C}$. The animals were kindly donated by Ellegaard Göttingen Minipig A/S, Dalmose, Denmark.

\section{Chemicals}

RNA isolation kit: NucleoSpin RNA II from Macherey-Nagel (AH diagnostics, Aarhus, Denmark), C-03, RT ${ }^{2}$ First Strand Kit from SABiosciences (Tebu-bio Aps., Roskilde, Denmark), Real-Time PCR reaction kit the LightCycler 480 SYBR Green I from Roche Diagnostics (Mannheim, Germany), Primers for the Real-Time PCR reaction were synthesized by TAG Copenhagen A/S (Copenhagen, Denmark). Gels for electrophoresis were purchased from GE Healthcare (Waukesha, WI, USA). The antibodies were obtained from BioSite (San Diego, CA, USA) cat. \# AP7898c (CYP3A7), Gentest (Prague, Czech Republic) cat. \# 458254 (CYP3A4), GE Healthcare cat. \# RPN1004 (anti-rabbit) and Dako Denmark A/S (Glostrup Denmark) code E0433 (anti-mouse). All other chemicals were of analytical grade.

\section{RNA extraction and first strand cDNA synthesis}

Total RNA was extracted from about $30 \mathrm{mg}$ of frozen liver tissue stored in RNA later at $18^{\circ} \mathrm{C}$ using the NucleoSpin RNA II kit (AH diagnostics) following the kit manual. The RNA concentration was determined by the Thermo Scientific NanoDrop 1000 spectrophotometer (Saveen Werner AB, Malmö, Sweden). Each sample was diluted to $250 \mathrm{ng} / \mu \mathrm{L}$ and $1.6 \mu \mathrm{L}$ was treated with $0.4 \mu \mathrm{L}$ DNA elimination buffer by incubation at $42^{\circ} \mathrm{C}$ in 5 minutes and subsequently put on ice for at least 1 minute. First Strand cDNA synthesis was performed using C-03, RT2 First Strand Kit (Tebu-bio Aps.) according to user's manual.

\section{Quantitative mRNA estimation, real-time polymerase chain reaction}

Primers for CYP3A4 (human), ${ }^{23}$ CYP3A7 (human) ${ }^{16,24}$ and reference genes: RPL4, SDHA and TBP (porcine) ${ }^{25}$ have been chosen on the bases of existing literature. Finally porcine primers were designed for CYP3A29 using a primer design tool at the National Center for Biotechnology Information (NCBI) homepage. ${ }^{26}$ Nucleotide sequences, species specificity and product sizes are listed in Table 1. Real-time PCR reaction was set up according to kit manual and optimized with respect to primer concentration, cDNA concentration and annealing temperature.

The final $20 \mu \mathrm{L}$ PCR reactions contained 20 ng of transcribed RNA and the primer concentrations $1 \mu \mathrm{m}$. The Multiwell Plate was loaded

Table 1. Primers used for polymerase chain reaction, product size and species specificity of the primers.

\begin{tabular}{|c|c|c|c|}
\hline Gene & Primer $\left(5^{\prime}-3^{\prime}\right)$ & $\begin{array}{l}\text { Product size } \\
\text { (bp) }\end{array}$ & $\begin{array}{c}\text { GeneBank } \\
\text { accession number }\end{array}$ \\
\hline $\begin{array}{l}\text { CYP3A29 } \\
\text { (sus scrofa) }\end{array}$ & $\begin{array}{l}\text { (f) GGGACCGTGGTGGTGGTGCCAGT } \\
\text { (r) TGCGGGGTCCAGTCCCAAAGGGCA }\end{array}$ & 151 & NM_214423* \\
\hline $\begin{array}{l}\text { CYP3A4 } \\
\text { (homo sapiens) }\end{array}$ & $\begin{array}{l}\text { (f) TGGTGAATGAAACGCTCAGATTA } \\
\text { (r) AGGGGGATCTGTGTTTCTTTACAA }\end{array}$ & 349 & NM_01746023 \\
\hline $\begin{array}{l}\text { CYP3A7-1 } \\
\text { (homo sapiens) }\end{array}$ & $\begin{array}{l}\text { (f) CCTTACCCCAATTCTTGAAGCA } \\
\text { (r) TCCAGATCAGACAGAGCTTTGTG }\end{array}$ & 198 & NM_000765 16 \\
\hline $\begin{array}{l}\text { CYP3A7-2 } \\
\text { (homo sapiens) }\end{array}$ & $\begin{array}{l}\text { (f) GATCTCATCCCAAACTTGGCCG } \\
\text { (r) CATAGGCTGTTGACAGGTCATAAATA }\end{array}$ & 241 & NM_000765 $5^{24}$ \\
\hline \multicolumn{4}{|c|}{ Reference gene } \\
\hline $\begin{array}{l}\text { RPL4 } \\
\text { (sus scrofa) }\end{array}$ & $\begin{array}{l}\text { (f) CAAGAGTAACTACAACCTTC } \\
\text { (r) GAACTCTACGATGAATCTTC }\end{array}$ & 122 & DQ845176 25 \\
\hline $\begin{array}{l}\text { SDHA } \\
\text { (sus scrofa) }\end{array}$ & $\begin{array}{l}\text { (f) CTACAAGGGGCAGGTTCTGA } \\
\text { (r) AAGACAACGAGGTCCAGGAG }\end{array}$ & 141 & DQ84517725 \\
\hline $\begin{array}{l}\text { TBP } \\
\text { (sus scrofa) }\end{array}$ & $\begin{array}{l}\text { (f) AACAGTTCAGTAGTCATGAGCCAGA } \\
\text { (r) AGATGTTCTCAAACGCTTCG }\end{array}$ & 153 & DQ84517825 \\
\hline
\end{tabular}

into the LightCycler ${ }^{\circledR} 480$ (Roche) and the following PCR program was used: pre-incubation for $2 \mathrm{~min}$ and then 40 cycles, denaturation $10 \mathrm{~s}$ at $95^{\circ} \mathrm{C}$, annealing $30 \mathrm{~s}$ at $56^{\circ} \mathrm{C}$ and synthesis 30 sec at $72^{\circ} \mathrm{C}$, followed by a melting curve analysis. Negative controls were set up omitting either the cDNA or primers.

Each sample and its associate $C Y P$ genes of interest was normalized on the basis of the mean of the three reference genes' Cp values, which served as an endogenous control functioning as a baseline. Thus the results are given as the relative expression of the gene of interest compared to the reference genes, using the formula: $N C Y \mathrm{P}=2^{\Delta \mathrm{CP}}$, where $N C Y \mathrm{P}$ is the $N$-fold expression of the $C Y P$ gene relative to baseline and $\Delta \mathrm{Cp}$ is the difference between $\mathrm{Cp}_{(\mathrm{CYP})}$ and $\mathrm{Cp}_{\text {(mean reference genes). }}$

\section{DNA isolation}

Chromosomal DNA was isolated using the illustra triplePrep Kit from GE Healthcare according to manual, and PCR reactions were set up using $50 \mathrm{ng}$ of DNA for each $20 \mu \mathrm{L}$ reactions.

\section{Isolation of liver microsomes}

The liver was homogenized in $15 \mathrm{~mL} 50 \mathrm{mM}$ Tris. HCl buffer containing $0.25 \mathrm{M}$ sucrose and $1 \mathrm{mM}$ ethylenediaminetetraacetic acid. The homogenate was centrifuged at $9000 \mathrm{xg}$ at $4^{\circ} \mathrm{C}$ for 30 minutes. Afterwards the supernatant was transferred to new tubes and once again centrifuged at $105,000 \mathrm{xg}$ at $4^{\circ} \mathrm{C}$ for $30 \mathrm{~min}$ utes. The supernatant was removed and the pellet containing the microsomes was resuspended and homogenized in storage buffer (0.154M KCl, 0.01M Hepes, 0.001M EDTA, 20\% glycerine, $\mathrm{pH} 7.6$ ), put on straws and frozen in liquid nitrogen.

\section{Western blotting}

Microsomal protein $(2 \mathrm{mg} / \mathrm{mL}, 20 \mu \mathrm{g} / \mathrm{lane})$ was separated by SDS-PAGE gel electrophoresis using the Multiphor II electrophoresis unit (Pharmacia, LKB Biotechnology AB, Uppsala, Sweden) and the Electrophoresis Power Supply - EPS 3500 from Pharmacia LKB Biotech. The proteins were transferred to a Hybond-ECL (GE Healthcare) nitro-cellulose membrane. The membrane was incubated 2 hours with the primary antibody, anti-human CYP3A7, diluted 137.5 times in $2 \%$ skimmed milk-TBS followed by the secondary antibody, anti-rabbit IgG, and the bands were visualized using the ECL reagents in combination with the UVP BioSpectrum ${ }^{\circledR}$ Imaging System (Upland, CA, USA). Afterwards the membrane was stripped, and incubation was repeated with anti-human CYP3A4 as the primary antibody and anti-mouse IgG as the secondary antibody, as described earlier. ${ }^{6}$ Human recombinant CYP3A7 and CYP3A4 proteins were used as positive controls.

\section{Statistics}

Univariate linear regression followed by the natural logarithm transformation and the analysis of variance (ANOVA) were conducted using $\mathrm{R}$ commander, version $1.5-4 .^{27} \mathrm{P}<0.05$ was accepted as a statistically significant difference. The factors age and sex were examined against CYP3A29 and CYP3A7-LE and additionally it was investigated if there were possible interaction between these factors. For the foetuses a time variable was included to investigate, whether gene expression was influenced by the time passed in minutes, from the dam was killed, to the foetal organs were frozen. 


\section{Results}

\section{Real-time polymerase chain reaction}

The expression of CYP3A7-LE and CYP3A29 were investigated and estimated from the mRNA level in the liver of 19 foetuses and 20 neonates Göttingen minipigs. Results are given as the relative expression of the respective CYP gene for the individual animal, that is, they reflect how many times ( $\mathrm{N}$-fold) the respective gene is expressed compared to the reference genes.

All of the Cp values for CYP3A7-LE were $>35$, which means that it was not possible to demonstrate an expression of CYP3A7-LE mRNA in the liver from Göttingen minipigs under the given circumstances.

In general the relative expression of CYP3A29 was higher for neonates than for foetuses (Figure 1). This was confirmed by the statistical data analysis, ANOVA, showing a significant difference in the relative expression of CYP3A29 in neonates compared to foetuses $\left(\mathrm{P}<5,208^{-16}\right)$, foetuses mean 0.0461 $(0.0371 ; 0.0649)$ and neonates mean 0.4252 $(0.243 ; 0.7441)$. The difference in CYP3A29 depending on age is visualized in Figure 2. CYP3A29 mRNA expression was approximately 9 -fold higher in neonates compared to foetuses, corresponding to an up regulation of more than $800 \%$ in comparison to foetuses. No sex differences were detected $(\mathrm{P}=0.65)$.

Positive result were obtained using chromosomal DNA and the CYP3A29 primers, whereas no amplification was obtained when using the CYP3A7-LE primer pairs.

\section{Western blotting}

Western blotting using a CYP3A7 primary antibody revealed nice single bands, with the immunochemically determined protein concentration being obviously higher for foetuses than for neonates (Figure 3).

The immunochemically determined protein concentration of CYP3A29 followed the same pattern as the results obtained from real-time PCR with highest concentration in the neonates (Figure 3).

\section{Discussion}

This is the first papers investigating and comparing the hepatic expression of CYP3A29 between foetuses and neonates Göttingen minipigs, and the first study that measures a CYP3A7-like enzyme in Göttingen minipigs. This is relevant as the human orthologues play a detrimental role in metabolising several xenobiotics in adults and foetuses respectively. ${ }^{17,28}$ Since the minipig is used as a model for humans in biomedical studies, it is important to clarify, whether this species expresses comparable CYP enzymes to humans of similar age. ${ }^{2,6}$ So far no single animal species stands out as being the best model for human foetal toxicity; however species used should exhibit similar rates as well as pathways of xenobiotic metabolism. ${ }^{22}$ The hepatic mRNA expression and protein level of the isoenzymes CYP3A29 and a CYP3A7-like enzyme of Göttingen minipig in the present study can provide valuable references for evaluating the usefulness of Göttingen minipig as model for human foetuses and neonates.

Results from human studies indicate that it should have been possible to measure the expression of a CYP3A7-like enzyme in both foetuses (gestational day 100 out of 114) and

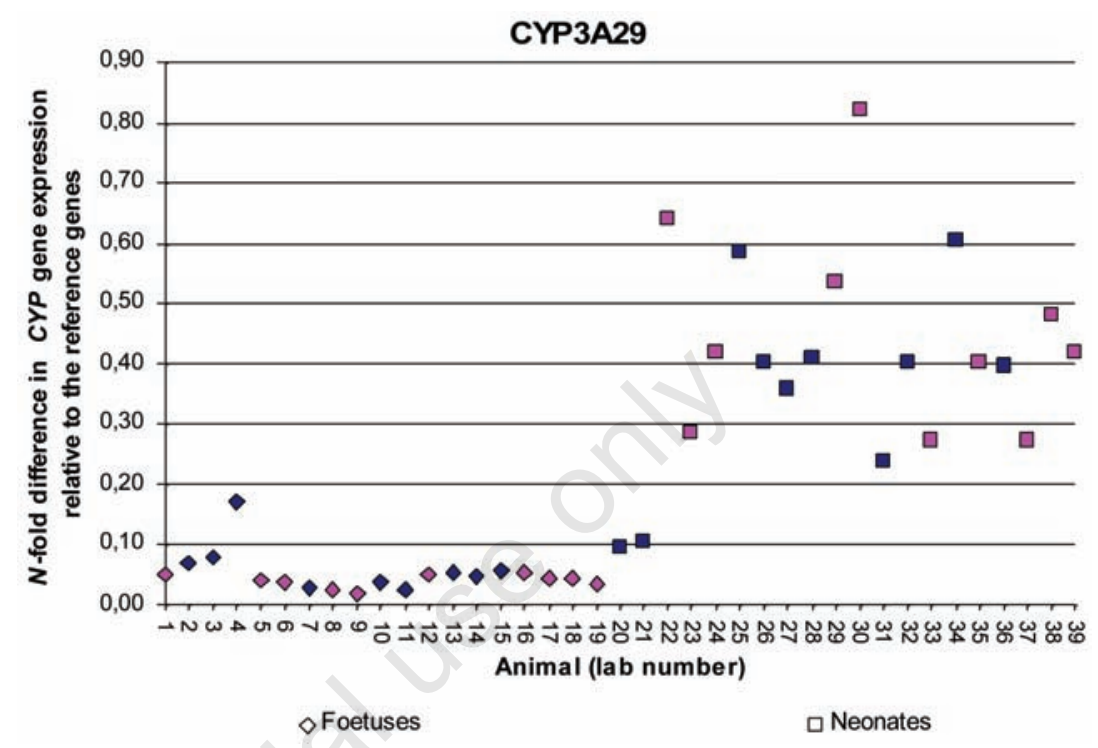

Figure 1. The relative expression of CYP3A29 for each individual Göttingen minipig depicted according to sex (pink: female, light blue: male). The animals were assigned consecutive laboratory numbers: animal no.1 to no. 19 are foetuses, while animal no. 20 to no. 39 are neonates.

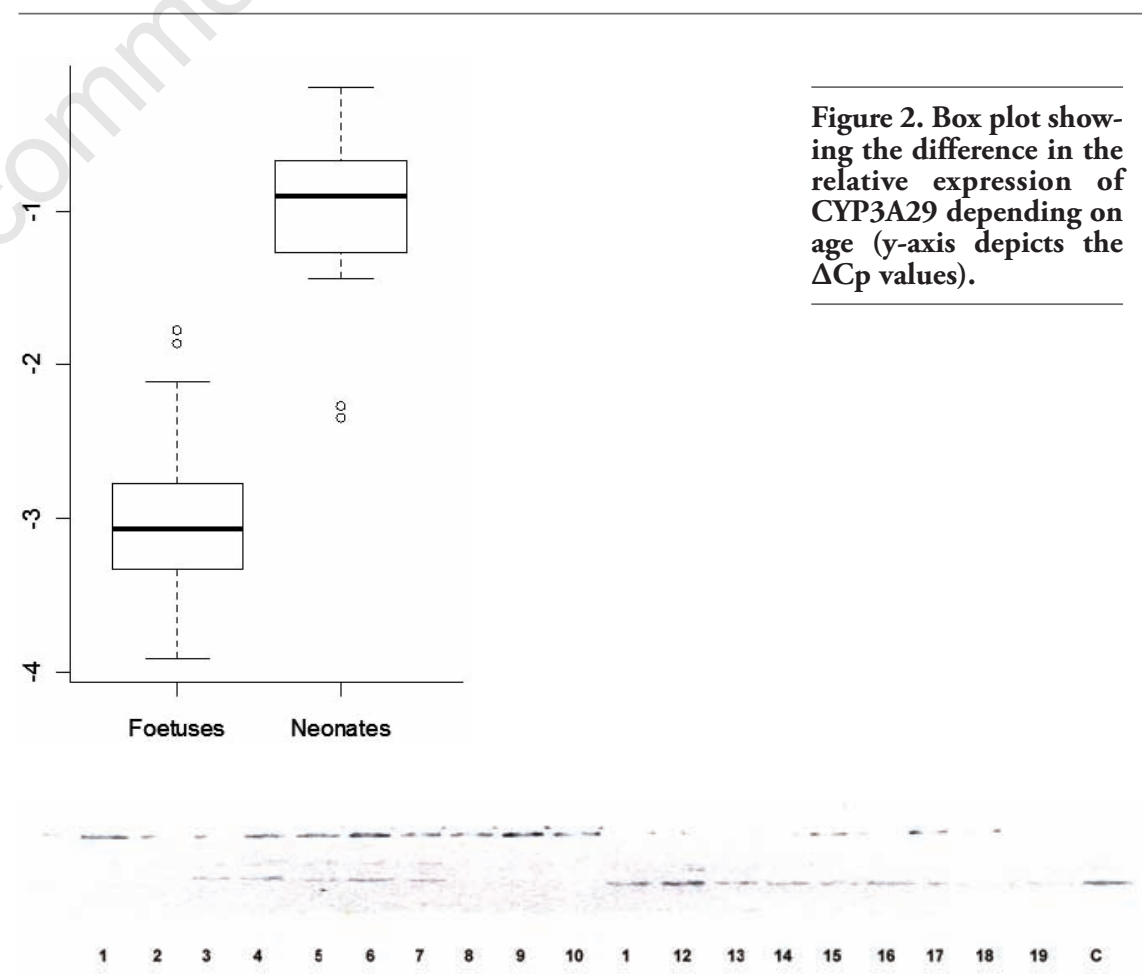

Figure 3. Western blot for 10 foetuses, lane 1-10, and 9 neonates, lane 11-19, female Göttingen minipigs. Upper lane incubated with anti-human CYP3A7, lower incubated with anti-human CYP3A4. 
neonates (approximately 24 hours old) Göttingen minipigs, if they transcribed such an enzyme with a similar expression pattern as CYP3A7 in humans. ${ }^{9,14,29}$ However this was not possible at mRNA level. There can be several potential explanations for this. It might be that the Göttingen minipigs included in the experiment did not express this gene, or, alternatively, the primers selected did not hybridize well. However western blotting revealed nice single bands and signals were visibly stronger for foetuses than for newborn Göttingen minipigs, indicating that there was a pre- or post transcription down regulation of a CYP3A7-like gene. This suggests that the primers used for real-time PCR have not been functional. Since the primers used in this experiment were of human origin, it is likely, that there exist some variation in the primerspecific regions between the human CYP3A7 and a CYP3A7-like gene in Göttingen minipig. Amplification reactions using chromosomal DNA confirmed that the primer pairs for CYP3A7 did not function, as no amplification was seen. However the bands appearing in the Western Blot could also be due to cross hybridization to other CYP3A variant.

Results from real-time PCR revealed that the relative expression of hepatic CYP3A29 in Göttingen minipigs was significantly different depending on age. This corresponds well with published results from studies dealing with the hepatic expression of CYP3A4 in human foetuses and neonates. ${ }^{9,15,18}$ A similar up regulation has been demonstrated for CYP3A4 in humans. Lacroix et al. ${ }^{9}$ found that the hepatic CYP3A4 mRNA level in human foetuses were less than $10 \%$ of the adult level. Recently the tissue distribution of CYP3A29 mRNA expression of Bama miniature pigs was investigated using real-time PCR. This study demonstrated an increasing hepatic mRNA expression level in Bama miniature pigs with the age: newborn, forty days, four months, six months and two years. ${ }^{18}$ The increasing level of CYP3A29 with age is consistent with the up regulation shown in neonates compared with foetuses. When comparing the results from real-time PCR and western blotting, these reflect similar expression patterns with weak or even missing for foetuses, whereas the bands are more pronounced for neonates Göttingen minipigs in line with the significant up regulation on mRNA level. Although still weak, the bands for CYP3A29 are visibly demonstrated for more neonates than foetuses. It is most likely that this tendency would have been more pronounced if the experiment had included even older minipigs. ${ }^{18}$

No sex difference of the relative CYP3A29 mRNA expression level appeared in neither foetuses or newborn Göttingen minipigs. This was in agreement with our expectations, as it previously was shown, that hormones regu- lates the CYP3A expression in pigs. ${ }^{23}$ Likewise no significant sex differences have been found for the hepatic CYP3A mRNA expression level neither in human foetuses ${ }^{30}$ nor at the CYP3A4 protein level in men and women. ${ }^{7}$

It was also shown that there is a slight interindividual variation in the CYP3A29 mRNA expression level. In this case this is mainly attributed to the genetic difference between individuals, as the Göttingen minipigs is from an outbred population. Similar results have been obtained for the CYP3A29 mRNA expression in Bama miniature pigs ${ }^{18}$ and for the CYP3A4 mRNA expression in humans, where a tenfold variation has been demonstrated..$^{30}$ Other possible factors which may have an influence on the expression level are for example the environment, pathology, hormonal or nutritional circumstances. These factors have, as far as possible, been eliminated in this experiment by using Göttingen minipigs of both sexes, bred under standardized conditions in a pathogen-free environment.

In conclusion the present study demonstrated that an up regulation of CYP3A29 both on transcriptional and translational level in neonates compared with foetuses occur. This shows that Göttingen minipigs exhibit a similar CYP3A4 like expression pattern as human foetuses and neonates of comparable age, indicating that the Göttingen minipig could be a good model when testing for foetal toxicity.

\section{References}

1. Bogaards JJ, Bertrand M, Jackson P, et al. Determining the best animal model for human cytochrome P450 activities: a comparison of mouse, rat, rabbit, dog, micropig, monkey and man. Xenobiotica 2000;30:1131-52.

2. Svendsen 0. The minipig in toxicology. Exp Toxicol Pathol 2006;57:335-9.

3. Meddahi A. Le miniporc comme modèle expérimental. Sci Tech Anim Lab 1994;19: 11-27.

4. Bollen P, Ellegaard L. The Göttingen minipig in pharmacology and toxicology. Pharmacol Toxicol 1997;80:3-4.

5. Anzenbacher P, Soucek P, Anzenbacherova $\mathrm{E}$, et al. Presence and activity of cytochrome P450 isoforms in minipig liver microsomes. Comparison with human liver samples. Drug Metab Dispos 1998; 26:56-9.

6. Skaanild MT, Friis C. Cytochrome P450 sex differences in minipigs and conventional pigs. Pharmacol Toxicol 1999;85:174-80.

7. Shimada T, Yamazaki H, Mimura M, et al. Interindividual variations in human liver cytochrome P-450 enzymes involved in the oxidation of drugs, carcinogens and toxic chemicals: studies with liver microsomes of 30 Japanese and 30 Caucasians. J Pharmacol Exp Ther 1994;270:414-23.

8. Wilkinson GR. Drug metabolism and variability among patients in drug response. $\mathrm{N}$ Engl J Med 2005;352:2211-21.

9. Lacroix D, Sonnier M, Moncion A, et al. Expression of CYP3A in the human liver -evidence that the shift between CYP3A7 and CYP3A4 occurs immediately after birth. Eur J Biochem 1997;247:625-34.

10. Nelson DR. The cytochrome p450 homepage. Hum Genomics 2009;4:59-65.

11. Danielson PB. The cytochrome P450 superfamily: biochemistry, evolution and drug metabolism in humans. Curr Drug Metab 2002;3:561-97.

12. Bieche I, Narjoz C, Asselah T, et al. Reverse transcriptase-PCR quantification of mRNA levels from cytochrome (CYP)1, CYP2 and CYP3 families in 22 different human tissues. Pharmacogenet Genomics 2007;17:731-42.

13. Komori M, Nishio K, Kitada M, et al. Fetusspecific expression of a form of cytochrome P-450 in human livers. Biochemistry 1990;29:4430-3.

14. Yang HY, Lee QP, Rettie AE, Juchau MR. Functional cytochrome P4503A isoforms in human embryonic tissues: expression during organogenesis. Mol Pharmacol 1994; 46:922-8.

15. Cresteil T. Onset of xenobiotic metabolism in children: toxicological implications. Food Addit Contam 1998;15 Suppl:45-51.

16. Nishimura M, Yaguti H, Yoshitsugu H, et al. Tissue distribution of mRNA expression of human cytochrome P450 isoforms assessed by high-sensitivity real-time reverse transcription PCR. Yakugaku Zasshi 2003;123:369-75.

17. Guengerich FP. Cytochrome P-450 3A4: regulation and role in drug metabolism. Annu Rev Pharmacol Toxicol 1999;39:1-17.

18. Shang H, Yang J, Liu Y, Wei H. Tissue distribution of CYP3A29 mRNA expression in Bama miniature pig by quantitative reverse transcriptase-polymerase chain reaction (RT-PCR). Xenobiotica 2009;39: 423-9.

19. Skaanild MT, Friss C. Characterization of the P450 system in Göttingen minipigs. Pharmacol Toxicol 1997;80 Suppl 2:28-33.

20 Anzenbacherova E, Baranova J, Zuber R, et al. Model systems based on experimental animals for studies on drug metabolism in man: (mini)pig cytochromes P450 3A29 and 2E1. Basic Clin Pharmacol Toxicol 2005;96:244-5.

21. Organisation for Economic Cooperation and Development (OECD): OECD guideline for the testing of chemicals. Proposal for updating guideline 414. Prenatal devel- 
opmental toxicity study. Adopted 22nd January 2001. Available from: http://www. oecd.org/dataoecd/18/15/1948482.pdf

22. Schardein JL, Schwetz BA, Kenel MF. Species sensitivities and prediction of tetratogenic potential. Environ Health Perspect 1985;61:55-67.

23. Gillberg M, Skaanild MT, Friis C. Regulation of gender-dependent CYP2A expression in pigs: involvement of androgens and CAR. Basic Clin Pharmacol Toxicol 2006;98:480-7.

24. Leeder JS, Gaedigk R, Marcucci KA, et al. Variability of CYP3A7 expression in human fetal liver. J Pharmacol Exp Ther
2005;314:626-35.

25. Nygard AB, Jorgensen CB, Cirera S, Fredholm M. Selection of reference genes for gene expression studies in pig tissues using SYBR green qPCR. BMC Mol Biol 2007;8:67.

26. U.S. National Library of Medicine. National Center for Biotechnology Information, NCBI. Available from: http://www.ncbi.nlm.nih.gov/ Accessed: October 2009.

27. Fox J. R Commander. Package 'Rcmdr' version 1.5-4. 2009. Available from: http://cs.swan.ac.uk/ csoliver/ok-satlibrary/OKplatform/ExternalSources/sourc
es/R/packages/Rcmdr.pdf

28. Marill J, Capron CC, Idres N, Chabot GG. Human cytochrome P450s involved in the metabolism of 9-cis- and 13-cis-retinoic acids. Biochem Pharmacol 2002;63:933-43.

29. Stevens JC, Hines RN, Gu C, et al. Developmental expression of the major human hepatic CYP3A enzymes. J Pharmacol Exp Ther 2003;307:573-82.

30. Schuetz JD, Beach DL, Guzelian PS. Selective expression of cytochrome P450 CYP3A mRNAs in embryonic and adult human liver. Pharmacogenetics 1994;4:11-20. 